\title{
A REINSERÇÃO NO MERCADO DE TRABALHO DO EMPREGADO REDUZIDO À CONDIÇÃO ANÁLOGA À DE ESCRAVO COMO MEIO DE CONCRETIZAÇÃO DOS DIREITOS HUMANOS
}

\author{
THE PLACEMENT OF THE PREVIOUSLY FORCED WORK VICTIMS: THE \\ CHALLENGE TO AVOID SIMILAR SLAVE CONDITIONS IN BRAZIL'S \\ CONTEMPORANY WORK ENVIRONMENT
}

Nathalia Canhedo ${ }^{1}$

RESUMO

O trabalho reduzido à condição análoga à de escravo completa, em 2015, cinquenta anos de sua existência no Brasil. Os trabalhadores são aliciados por terceiros para uma jornada exaustiva, degradante, sem o mínimo de condições salubres para a sobrevivência, ferindo um dos maiores fundamentos da República Federativa do Brasil, a dignidade da pessoa humana. Ainda que cause estranheza, o tema é atual e de suma importância, tendo em vista a transgressão de direitos elementares do ser humano. Além da busca incessante pelo combate ao escravismo contemporâneo há ainda uma enorme preocupação na reinserção do empregado no mercado de trabalho. O objetivo do presente trabalho, portanto, é averiguar se os poderes públicos têm atuado na criação de programas sociais que visem não apenas à erradicação do trabalho forçado, mas também o acompanhamento dos trabalhadores capturados para que possam retornar de forma digna ao mercado de trabalho, com a profissionalização e a capacitação da mão de obra. Para tanto, utilizar-se-á especialmente a investigação histórica, por meio de método dedutivo, com auxílio da pesquisa descritiva e bibliográfica sobre o tema. Ao final, pode-se concluir que, embora já existam em alguns Estados iniciativas de programas sociais de reinserção do trabalhador no mercado, fato é que tais empreendimentos ainda são muito pequenos diante da gravidade do problema. E mais, o alto índice de retorno ao trabalho forçado obsta a esses empregados a concretização de seus direitos humanos, o que deve ser rechaçado pela sociedade moderna.

Palavras-Chave: Trabalho escravo contemporâneo. Dignidade da pessoa humana. Reinserção no mercado de trabalho.

\footnotetext{
${ }^{1}$ Graduada pela Universidade Federal do Tocantins. Pós Graduada pela Faculdade Damásio de Jesus. Assessora Jurídica na Procuradoria Geral do Estado do Tocantins. Email: nathicanhedo@gmail.com
} 


\begin{abstract}
Work seen as similar conditions as that of a slave celebrates its $50^{\text {th }}$ anniversary in Brasil. Workers are lured by third parties for an exhaustive and degrading work condition, not being offered the basic conditions for survival, disrespecting on of the greatest pillars of Brazil's foundations, the human being dignity. Despite the appaling reaction of some to this matter, this is of utmost importance, for it disregards the very essential rights that human beings are entitled to. Besides the efforts to ban contemporary slavery there's still a massive concern on job replacement in the work market. The purpose of this essay is to closely check if the Brazil. If Brazil's public authorities have taken measures to promote social programs aimed at not only banning forced work but also the assistance for the previously captured to the job market in a proper manner by means of training and enabling this work force. In order to achieve that, one shall especially utilize historic survey, through the deductive method with support of descriptive and bibliographic approach on the topic. Eventually on shall come to the conclusion that in spite of the existence in some states of initiatives. In the social realm to place the worker back to the job market such measures are far from sufficient to effectively tackle the issue. Also the high rate of going back to forced work hinders these workers the fulfillment of their human rights, wich must be fiercely defended by modern society.
\end{abstract}

Key-words: Contemporary slave job. Human being dignity. Replacement in the job market.

\title{
1 CONSIDERAÇÕES INICIAIS
}

A escravidão, embora pareça algo muito antigo, ainda está enraizada em nossos costumes, mesmo em pleno século XXI, uma vez que vemos na mídia e até mesmo em redes sociais ${ }^{2}$ notícias atuais de trabalhadores que estavam laborando em condições análogas à de escravo.

Infelizmente tais situações representam ainda muito dos trabalhadores brasileiros, seja na zona urbana ou rural, violando um dos principais direitos humanos, o direito à liberdade, o direito de ir e vir livremente.

É preciso ressaltar que o trabalho reduzido à condição análoga à de escravo está relacionado ao cerceamento da liberdade. Contudo essa liberdade não está atrelada tão somente à ideia de constrangimento físico, mas especialmente moral, que é um dos grandes focos para o combate do trabalho escravo.

Segundo a Organização Internacional do Trabalho - OIT, a impunidade

${ }^{2}$ O Min. Trabalho fez 3.643 inspeções de 1995 a maio/2014. O MPF ajuizou 1.601 ações penais por trabalho escravo no período. Disponível em: 〈https://twitter.com/WSarai/status/520577769751605250>. Acesso em: 10 set. 2015. 
daqueles que reduzem o trabalhador à condição análoga à de escravo é um dos grandes empecilhos à erradicação do escravismo contemporâneo.

A realidade social em que se inserem essas pessoas leva-as a tal situação para sua própria sobrevivência, fazendo-as acreditar que estar submetido a jornadas exaustivas e trabalhos forçados é comum.

As pessoas que são encontradas submetidas ao trabalho escravo contemporâneo, que é aquele que não cerceia apenas a liberdade do ser humano, mas a própria dignidade da pessoa humana, sobrevivem em situação degradante.

Engana-se quem pensa que essas situações ocorrem tão somente no meio rural. Ao contrário, já foram encontrados vários trabalhadores em condições análogas à de escravo em grandes centros urbanos, especialmente nos serviços de confecção e construção civil.

Denota-se, portanto, que o tema trabalho reduzido à condição análoga à de escravo é atual e de extrema importância, estando intrinsicamente ligado aos direitos humanos, aos direitos sociais, à dignidade da pessoa humana, sendo o seu debate acadêmico de grande valia para a construção de ideias que visem à sua erradicação.

Importante frisar que o valor social do trabalho é um dos fundamentos da República Federativa do Brasil, previsto no artigo 1ำ inciso IV da Constituição Federal, não bastando que a Carta Magna resguarde o direito a tal trabalho, mas que esse seja também digno.

A dignidade da pessoa humana, característica inerente a todo ser humano, é imposta ao Estado para que este, por meio de ações sociais, a preserve e a garanta a todos os cidadãos.

Contudo, quando se fala hoje em trabalho escravo contemporâneo, denota-se que não é possível alcançar essa dignidade se as pessoas ainda são submetidas a jornadas exaustivas e trabalhos degradantes, concluindo-se que o Estado não tem feito o bastante para garantir essa dignidade ao trabalhador.

Cabe ao Ente Público assegurar a todo trabalhador condições mínimas e dignas de trabalho, que devem, por óbvio, ser respeitadas por ele e por toda sociedade.

Neste estudo, portanto, pretende-se fazer uma busca das origens dessa anomalia e o motivo para que ainda hoje ela continue acontecendo, especialmente nos casos em que trabalhadores retirados de tal situação retornam a ela depois de 
algum tempo.

O que parece acontecer é que a escravidão no Brasil foi apenas formalmente proibida por meio da Lei Áurea de 1888, há quase 127 anos, mas permanece na sociedade até os dias hodiernos, só que sob outra roupagem, evidenciando-se ainda a transgressão dos direitos humanos e fundamentais desses trabalhadores.

Impende registrar que foi promulgada a Emenda Constitucional - EC n. 81/2014, a qual modificou o artigo 243 da Constituição Federal ${ }^{3}$, em que as terras onde for encontrada exploração de trabalho escravo serão expropriadas e destinadas à reforma agrária e programas de habitação popular.

A mudança de tal dispositivo constitucional reforça mais a punibilidade daqueles que submetem seres humanos a trabalho forçado e degradante, com jornadas excessivas e exaustivas.

Importante também destacar que as medidas judiciais hoje existentes que atuam em prol desse trabalhador no aspecto do pós-regaste ainda não são efetivas, uma vez que não existem políticas públicas suficientes que busquem reinserir o trabalhador no mercado de trabalho de forma profissionalizada.

A escravidão, portanto, passou a ser uma das maiores vergonhas da humanidade, e para chegar a tal conclusão, não é preciso assistir aos filmes '12 Anos de Escravidão' ou o 'Êxodo', bastando observar o próprio País ou até mesmo o estado do Tocantins, pois se verá que não se está tão distante das eras da escravidão.

Diante desse cenário, este trabalho visa a responder à seguinte indagação: as políticas públicas existentes hoje são suficientes para garantir uma reinserção digna do trabalhador ao mercado de trabalho como forma de concretização de seus direitos humanos?

Importante destacar que para o trabalho será utilizada a investigação histórica do tema proposto, com a utilização do método dedutivo, além do auxílio da pesquisa descritiva e bibliográfica do objeto em estudo.

Respondendo à pergunta acima descrita, o produto final do trabalho será a verificação das medidas judiciais que hoje são postas em prol do trabalhador para

\footnotetext{
${ }^{3}$ Art. 243. As propriedades rurais e urbanas de qualquer região do País onde forem localizadas culturas ilegais de plantas psicotrópicas ou a exploração de trabalho escravo na forma da lei serão expropriadas e destinadas à reforma agrária e a programas de habitação popular, sem qualquer indenização ao proprietário e sem prejuízo de outras sanções previstas em lei, observado, no que couber, o disposto no art. $5^{\circ}$. (Redação dada pela Emenda Constitucional n ${ }^{\circ} 81$, de 2014).
} 
sua reinserção no mercado de trabalho como forma de lhe proporcionar o acesso à justiça material e não meramente formal, além da constatação ou não de políticas públicas existentes para auxiliar esse retorno a novos meios de labor, bem como a verificação do papel do Poder Judiciário para a concretização de tais ideais.

\section{O EFETIVO COMBATE AO TRABALHO ESCRAVO CONTEMPORÂNEO E A REINSERÇÃO DO TRABALHADOR NO MERCADO DE TRABALHO}

O tema do trabalho escravo é algo que assola a humanidade desde os tempos mais remotos, ou seja, antes de Cristo, quando os faraós escravizaram o povo hebreu no Egito, como pode se depreender da leitura de obras e artigos que versam sobre $o$ assunto.

No entanto a escravidão contemporânea não é a mesma retratada na história do Brasil Colônia ou Império, caracterizando-se hodiernamente pelo afrontamento da Dignidade da Pessoa Humana, fundamento da República Federativa do Brasil.

A Organização Internacional do Trabalho, em sua Convenção n. 29, ratificada pelo Brasil, preleciona em seu artigo $2^{\circ}$ que "O trabalho forçado ou obrigatório designará todo trabalho ou serviço exigido de um indivíduo sob ameaça de qualquer penalidade e para o qual ele não se ofereceu de espontânea vontade."

No Brasil, o trabalho análogo ao de escravo é definido pelo artigo 149 do Código Penal, que dispõe:

Artigo 149. Reduzir alguém à condição análoga à de escravo, quer submetendo-o a trabalhos forçados ou a jornada exaustiva, quer sujeitando-o a condições degradantes de trabalho, quer restringindo, por qualquer meio, sua locomoção em razão de dívida contraída com o empregador ou preposto.

Depreende-se, assim, que o escravismo contemporâneo não é determinado tão somente por infração às leis trabalhistas, sendo também um crime contra a dignidade humana, passível de punição de 2 (dois) a 8 (oito) anos de reclusão, além de multa.

O trabalho escravo, portanto, caracteriza-se por ser um trabalho forçado, com jornada exaustiva, em condições degradantes, além da existência de servidão por dívida. 
No entanto, Samuel A. Antero (2008, p. 03) ensina que o "trabalho escravo é muito mais que o descumprimento da lei trabalhista", merecendo grandes reflexões o tema no seu aspecto sociológico, histórico, cultural, político, econômico e, por fim, legal.

No mesmo sentido, Luciana Paula Conforti (2014, p. 01) ensina que

O trabalho escravo é a forma mais grave de exploração do ser humano e não atenta apenas contra os princípios e direitos fundamentais do trabalho, afrontando também os mais elementares direitos humanos, como a vida, a liberdade e a dignidade do trabalhador.

As condições de trabalho dessas pessoas são degradantes: o alojamento é precário, vivendo muitas vezes em barracos de lona em chão de terra; falta assistência médica; a alimentação é péssima; não há saneamento básico e água potável; além da possibilidade de existirem maus-tratos e violência.

Segundo dados da Organização Internacional do Trabalho - OIT, existem hoje no mundo doze milhões e trezentos mil $^{4}$ trabalhadores em regime de trabalho análogo à escravidão (na América Latina e Caribe são 1.320 .000 milhões), e 60\% (sessenta por cento) dos obreiros que são encontrados em tal condição retornam à exploração.

Já a Comissão Pastoral da Terra $\left(2015^{5}\right)$ calcula que, entre os trabalhadores resgatados de 2003 a 2014, 23,6\% são migrantes do Maranhão, 9,4\% da Bahia, $8,9 \%$ do Pará, 8,3\% de Minas Gerais, 5,6\% do Tocantins, 5,5\% do Piauí e 5,5\% do Mato Grosso.

Esses trabalhadores em sua grande maioria são homens com uma faixa etária predominante entre 18 e 44 anos, sendo 33\% analfabetos e tendo a maioria deles laborado em condições análogas à de escravo na produção de cana de açúcar (25\% de 50 mil resgatados entre 2003-2014).

Dados fornecidos também pela Comissão Pastoral da Terra (2015) demonstram que no interregno de 2003 a 2014 foram libertados 2.162 (dois mil cento e sessenta e dois) trabalhadores em condições análogas à de escravo no Estado do Tocantins, número bastante significativo.

\footnotetext{
${ }^{4}$ Disponível em: <http://www.oit.org.br/sites/all/forced_labour/oit/relatorio/indicadores.pdf〉. Acesso em: 10 set. 2015.

${ }^{5}$ Dados fornecidos pela CPT - Comissão Pastoral da Terra. Data: 07 de Janeiro de 2015.
} 
A Declaração Universal dos Direitos Humanos de 1948 proclamou em seus três primeiros artigos os valores fundamentais da liberdade, da igualdade e da fraternidade. Portanto, ao asseverar que "toda pessoa tem direito à vida, à liberdade e à segurança pessoal, reitera o princípio de que ninguém será mantido em escravidão ou servidão, proibindo, de forma absoluta, a escravidão e o tráfico de escravos" (SILVA, 2010, p. 36).

No entanto, e infelizmente, nos dias atuais, encontramos seres humanos sendo submetidos ao trabalho forçado, transgredindo-se, assim, o direito humano à liberdade, ferindo a dignidade da pessoa humana e expondo o trabalhador à jornada exaustiva e degradante, golpeando os mais elementares direitos fundamentais.

Com isso, conclui-se que o trabalho degradante das eras da escravidão ainda permanece enraizado na sociedade, sendo um mal a ser combatido, pois viola a Declaração dos Direitos Humanos e a dignidade da pessoa do trabalhador.

Paulo Henrique Costa Mattos (2014, p. 2) assevera que

As piores correntes da escravidão no Brasil ou em qualquer parte do mundo não são aquelas que prendem as mãos, os pés ou os corpos dos indivíduos, mas aquelas que prendem a mente, que submetem pessoas a uma condição de trabalho que não os tornam livres, mas oprimidos, dependentes e condenados a uma condição de aviltamento da condição humana, que impede o ser humano de realizar os seus sonhos, escolher seus próprios caminhos e aceitar de forma resignada a escravidão.

Como já ressaltado anteriormente, o trabalho escravo configura-se pelo trabalho degradante e também pelo cerceamento de liberdade. No entanto "este segundo fator nem sempre é visível, uma vez que não mais se utilizam correntes para prender o homem a terra, mas sim ameaças físicas, terror psicológico" (SAKAMOTO, 2007, p. 27).

Diante dessa realidade, depreende-se que o escravismo contemporâneo é tema de grande relevância social, merecendo o estudo não somente das consequências do mesmo, mas principalmente o real motivo de sua manutenção.

Sobre isso, Nicanor Fávero Filho (apud PIOVESAN; CARVALHO, 2010, p. 248) preleciona que

O Brasil, ao possuir ainda trabalhadores prestando serviços em condições análogas à de escravo, não pode se outorgar o direito de se considerar plenamente um Estado Democrático de Direito, pois a 
dignidade humana, que permeia todos os princípios de sua Constituição, não está sendo garantida, causando graves ranhuras aos direitos fundamentais e difusos previstos.

Samuel A. Antero (2008, p. 06) ensina também que

A erradicação do trabalho escravo talvez seja um dos poucos problemas sociais que, se corretamente instrumentalizado, pode ser extinto em curto prazo. Entretanto, é necessário focalizar mais nas causas do problema do que em suas consequências.

A preocupação em combater o trabalho forçado vem de diversos órgãos públicos e também da sociedade, uma vez que permiti-lo ainda é aceitar que a escravidão não acabou de fato.

Órgãos como Ministério Público do Trabalho - MPT, Polícia Federal e Ministério do Trabalho e Emprego - MTE têm procurado o combate ao trabalho escravo especialmente quanto à investigação, à captura dos trabalhadores e ao pagamento dos débitos trabalhistas.

Contudo muitos desses trabalhadores acabam voltando à situação degradante, posto que não encontram amparo para sua reinserção no mercado de trabalho no aspecto do pós-resgate.

No estado do Mato Grosso, por exemplo, já foi implantada uma experiência bem sucedida de reinserção social e profissional das vítimas de trabalho análogo à escravidão (MELO, 2013).

Referido programa foi criado em parceria com o Sindicato Nacional dos Auditores do Trabalho - SINAIT e OIT, obtendo-se bom resultado, que inclusive poderia auxiliar outros Estados, como o Tocantins, na criação de algo semelhante.

Recentemente, no dia 18 de agosto de 2015, o presidente do Tribunal Superior do Trabalho - TST, Ministro Barros Levenhagen, assinou um termo de cooperação para o fortalecimento do Movimento Ação Integrada - MAI, que visa ao fortalecimento da articulação de reinserção social dos trabalhadores resgatados em situações de trabalho escravo.

Denota-se com isso que existe uma preocupação em nível nacional de combate efetivo ao trabalho escravo, bem como de reinserção de forma digna do trabalhador em condição análoga à de escravo no mercado de trabalho.

Todavia não bastam termos de cooperação, é imprescindível que sejam 
criadas condições efetivas de reinserção social e profissional aos trabalhadores resgatados e vulneráveis ao trabalho escravo, por meio de acolhimento e acompanhamento psicossocial, formação em cidadania, elevação educacional, qualificação profissional e inserção em políticas públicas de emprego e renda.

Para que esse fim seja alçado, é necessária também a propositura de medidas judiciais que tenham por finalidade que o Poder Executivo implante políticas públicas para a reinserção do trabalhador resgatado. Isso colaboraria para o retorno do trabalhador de forma digna, evitando que se submeta a jornadas degradantes e exaustivas novamente.

Aliás, o ordenamento jurídico brasileiro oferece mecanismos para que o Poder Judiciário viabilize adequadamente a efetivação dos direitos desses trabalhadores, especialmente por meio de Ação Civil Pública, com cominação em obrigação de fazer para que o Executivo implemente programas de profissionalização do trabalhador, sob pena de incidência de multa e até bloqueios de dinheiro do orçamento de referido poder.

Ao Judiciário cabe uma postura mais ativa e transformadora em face dos problemas sociais, impondo, quando da propositura dessas medidas judiciais, que verbas públicas sejam destinadas para a criação de tais programas sociais e da justiça itinerante, em que toda estrutura do judiciário atue em regiões distantes dos grandes centros e com pouco acesso à justiça, para facilitar o combate ao trabalho escravo e a punibilidade dos empregadores.

Esses trabalhadores, quando são resgatados da situação de escravidão, correm um risco alto de serem vítimas novamente da exploração, uma vez que regressam para a mesma vulnerabilidade e tendem a aceitar um trabalho mal pago e sem garantias de respeito aos direitos do trabalhador.

Por isso é que o Poder Público e as Organizações da sociedade civil precisam se dedicar ao combate dessa grave violação de direito humanos, por meio da prevenção ao problema, assistência ao trabalhador resgatado e repressão ao crime.

É preciso que haja medidas judiciais e mecanismos jurídicos de maior eficácia no pós-resgate do trabalhador para que o índice de regresso a tais situações diminua ou até mesmo deixe de existir de forma concomitante com a existência de políticas públicas que objetivem a mesma finalidade.

Ao que tudo indica, os instrumentos apresentados hoje a esses trabalhadores 
não são eficazes o bastante e obstam seu acesso à justiça. Isso porque o direito do acesso à justiça significa um direito formal do indivíduo de poder propor ou contestar uma ação e, para Mauro Cappelleti e Bryant Garth (1998, p. 9), "o acesso formal, mas não efetivo à justiça, correspondia à igualdade formal, mas não efetiva".

Tem-se, assim, que o verdadeiro acesso ao Poder Judiciário hoje visa não apenas a proclamar os direitos do cidadão, mas, principalmente, fazer com que esses direitos conferidos sejam realmente garantidos a todos.

Portanto, quando o instrumento posto à disposição da parte for insuficiente para alcançar o fim, por consequência, o trabalhador acabará retornando ao trabalho degradante.

Sendo assim, não basta que o trabalhador seja capturado, que seus direitos trabalhistas sejam pagos, se quando ele procura novamente emprego percebe que não tem qualidade profissional para almejar outra ocupação. Isso não significa um verdadeiro acesso à justiça, já que a esse obreiro são impostos obstáculos para que ele tenha um trabalho digno.

Wantiul Luiz Cândido Holz (2006, p. 8) assevera que

A atividade jurisdicional deve ser eficaz, devendo ir além da construção in causu do comando normativo, de modo a garantir sua aplicação no mundo fático, ou seja, deve fazer com que a decisão ultrapasse as portas do judiciário para erradiar efeitos práticos no âmbito da sociedade. O cidadão, ao bater às portas do judiciário, não pretende ter em mãos uma sentença favorável, pretende sim ter a entrega do bem da vida do processo.

O acesso ao Poder Judiciário se faz pilar do Estado Democrático de Direito, sendo requisito fundamental de um sistema jurídico moderno e igualitário, em que se pretenda garantir e não apenas proclamar os direitos. A eficácia desse acesso apenas será alcançada quando se obtiver no plano concreto os resultados previstos na lei.

Deve haver programas para profissionalização do obreiro, uma vez que a "vulnerabilidade dos trabalhadores ao aliciamento para o trabalho escravo se dá principalmente pela precariedade dos sistemas produtivos locais em gerar trabalhos dignos para a população" (OLIVEIRA, 2011, p. 9).

A criação também de um núcleo especializado em combate ao trabalho 
escravo já obteve sucesso em alguns estados, tal como Maranhão ${ }^{6}$ e Bahia ${ }^{7}$, podendo servir de modelo para que no Tocantins também seja adotada uma estratégia ainda maior de combate à escravidão contemporânea.

Os meios jurídicos e o Poder Judiciário devem auxiliar para que, por meio de ações judiciais, o Executivo crie em nível estadual um programa de profissionalização das pessoas que são encontradas na condição de trabalho escravo. Assim, no momento da captura, não haveria somente o pagamento dos débitos trabalhistas, mas também que se teria uma preocupação com o destino profissional dos mesmos, uma vez que sem condições nesse sentido acabam retornando ao labor degradante.

Necessário se enfrentar o trabalho escravo com ações no âmbito estadual, em conjunto com os poderes Executivo, Legislativo e Judiciário, além do auxílio do Ministério Público, para que essa realidade seja de vez modificada.

O que ocorre na prática é que há uma busca real pela liberdade do trabalhador, passando pela repressão do ilícito, mas sem uma atuação efetiva na implementação de ações preventivas e políticas públicas para a inclusão social do trabalhador resgatado do escravismo contemporâneo.

A mentalidade e o comportamento escravocrata ainda subsistem, aprofundando-se ainda mais o abismo das desigualdades sociais, econômicas, raciais e culturais, o que contribui muito para a manutenção do trabalho forçado até hoje.

O Ministério do Trabalho e Emprego, por meio da Portaria n. 540/2004, criou o Cadastro de Empregadores Infratores, mais conhecido como "Lista Suja". Consiste em um cadastro dos empregadores que submetem trabalhadores a condições análogas à de escravo com o propósito de cancelamento de financiamentos por bancos públicos, entre outras consequências de cunho patrimonial, além do seu caráter pedagógico.

Em dezembro de 2014, todavia, o Supremo Tribunal Federal - STF suspendeu, por meio de uma liminar, a publicação da lista suja de empregadores, documento que era semestralmente atualizado pelo MTE.

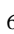

Disponível

em: <http://www7.semu.ma.gov.br/index.php?option=com_content\&view=article\&id=314:maranhao-instala-o-16onucleo-de-enfrentamento-ao-trafico-de-pessoas-do-pais\&catid=8:noticiaultima\&Itemid=90>. Acesso em: 10 set. 2015.

${ }^{7}$ Disponível em: <http://www.cljornal.com.br/antigo-site/noticia.php?id=9684>. Acesso em: 10 set. 2015. 
Felizmente, três meses após a liminar, houve a edição de uma nova portaria interministerial, em que foi recriado o cadastro de empregadores flagrados com mão de obra análoga à de escravo, utilizando a Lei de Acesso à Informação como embasamento legal para sua manutenção.

Contudo a criação da lista suja é apenas uma entre tantas possibilidades que podem ser feitas para o combate do escravismo contemporâneo.

A atuação de órgãos como o MPT e MTE é basicamente reativa, ou seja, baseia-se em denúncias recebidas para então poder entrar em ação.

O que se faz necessário é prevenir toda essa situação, criando-se uma rede interligada de ações sociais de capacitação dos trabalhadores, educação, atuandose na base, e não apenas na capturação.

A preocupação que se tem com relação ao pós-resgate é justamente de evitar que os trabalhadores sejam novamente aliciados e retornem ao trabalho forçado. Portanto, é preciso "combater as causas da escravidão contemporânea, destacandose a impunidade, a pobreza e o modelo econômico concentrador de renda e gerador de exclusões sociais" (OLIVEIRA, 2011, p. 12).

Não basta apenas um ramo do Poder ou da sociedade se mobilizar para o combate do trabalho forçado, merecendo esforços de todos para que haja, de uma vez por todas, a erradicação do trabalho reduzido à condição análoga à de escravo, bem como o auxílio para que o empregado consiga retornar ao mercado laborativo de uma forma digna e saudável, quebrando o ciclo vicioso em que se insere.

\section{CONCLUSÃO}

A submissão de trabalhadores à condição análoga à de escravo infelizmente ainda é realidade no século $\mathrm{XXI}$, embora não possua mais os contornos da escravidão de outrora.

No entanto a prevalência ainda do trabalho forçado revela-se como uma mácula social que precisa ser banida, pois não se coaduna com o Estado Democrático de Direito e com os direitos individuais e sociais previstos na Carta Magna, especialmente o da dignidade da pessoa humana.

Embora já existam alguns programas sociais bem desenvolvidos em alguns estados da Federação, tal como Mato Grosso, Bahia e Maranhão, que se 
preocupam com a profissionalização dos trabalhadores resgatados no trabalho escravo, fato é que os mesmos atendem apenas a demandas regionais, não se estendendo a outros Estados.

Infere-se que no Brasil a parceria público-privada para a implementação de políticas sociais de reinserção do empregado no mercado de trabalho é quase ínfima.

Já existem alguns projetos lançados pelo Sindicato dos Auditores do Trabalho - SINAIT, Movimento Ação Integrada - MAI, Conselho Nacional de Justiça - CNJ, TST, MTE e demais órgãos que se preocupam de fato com a reinserção profissional e social das vítimas de trabalho escravo.

Contudo essas ações sociais têm ocorrido a passos lentos ante a gravidade do caso e do grande número de trabalhadores que são captados todos os anos. Apenas no período compreendido entre 2003 a 2014 foram resgatados aproximadamente 22.325 (vinte e dois mil trezentos e vinte e cinco) trabalhadores em todo Brasil, conforme dados da Comissão Pastoral da Terra - CPT (2015).

Segundo a OIT, desse quantitativo de empregados, a maioria - 60\% - é reincidente no trabalho escravo, uma triste realidade, demonstrando que o ciclo é altamente vicioso e que é preciso quebrar a corrente, com atenção especial na profissionalização desses trabalhadores quanto ao pós-resgate.

O Movimento Ação Integrada tem como foco justamente qualificar os trabalhadores resgatados, oferecendo paralelamente cursos de elevação da escolaridade para, posteriormente, inseri-los no mercado de trabalho formal. Dessa forma, quebra-se o circuito da vulnerabilidade desses trabalhadores, devolvendoIhes a cidadania.

Acontece que o projeto do MAI inicialmente será apenas para São Paulo e Rio de Janeiro, estados com baixo resgate de trabalhadores em situação análogas à de escravo, uma vez que o grande número de captura está no Nordeste e CentroOeste.

Portanto, conclui-se que de fato as políticas públicas existentes são bastante insignificantes frente ao grande número de trabalhadores vivendo em condições de trabalho escravo contemporâneo.

Por outro lado, os meios jurídicos para a prevenção do trabalho escravo, bem como para a criação de políticas públicas, embora disponíveis, são ainda pouco utilizados, uma vez que a atuação do MPT e MTE, notadamente, é meramente 
reativa, ou seja, apenas ocorre quando há provocação e instauração de procedimento interno.

Tanto a população como os órgãos judiciais e não judiciais precisam buscar medidas mais efetivas para garantir aos trabalhadores capturados uma reinserção digna no mercado formal de trabalho, já que o índice de retorno ao labor degradante é bastante significativo, como dantes ressaltado.

O que se espera é que os direitos humanos possam ser efetivamente garantidos a todas as pessoas, seja por meio judicial, seja por meio de políticas públicas criadas pelo Executivo como forma de se alcançar a justiça, banindo da sociedade a figura do trabalho escravo de uma vez por todas.

\section{REFERÊNCIAS}

ANTERO, Samuel A. Monitoramento e avaliação do Programa de Erradicação do Trabalho Escravo. Rev. Adm. Pública vol.42 no.5 Rio de Janeiro Sept./Oct. 2008. Disponível em: <http://www.scielo.br/scielo.php?script=sci_arttext\&pid=S0034$76122008000500002 \& l a n g=p t \# n t>$. Acesso em: 18 dez. 2014.

BRASIL. Constituição da República Federativa do Brasil de 1988. Disponível em: <http://www.planalto.gov.br/ccivil_03/constituicao/constituicaocompilado.htm>. Acesso em: 18 dez. 2014.

. Decreto-Lei n 2.848, de 7 de dezembro de 1940. Código Penal. Disponível em <http://www.planalto.gov.br/ccivil_03/decretolei/Del2848compilado.htm>. Acesso em: 10 set. 2015.

. Emenda Constitucional n. 81 de 5 de junho de 2014. Dá nova redação ao $\overline{\text { art. } 243}$ da Constituição Federal. Disponível em:

<http://www.planalto.gov.br/ccivil_03/constituicao/Emendas/Emc/emc81.htm>. Acesso em: 10 set. 2015.

BRILHO FILHO, José Cláudio Monteiro de. Trabalho com Redução do Homem à Condição Análoga à de Escravo e Dignidade da Pessoa Humana. Disponível em: $<$ http://www.oit.org.br/sites/all/forced_labour/brasil/documentos/dignidadetrabalhoesc ravo.pdf>. Acesso em: 10 set. 2015.

CAPPELLETTI, Mauro; GARTH, Bryant. Acesso à Justiça. Porto Alegre: Fabris, 1998.

CPT. Comissão Pastoral da Terra. Disponível em: < http://www.cptnacional.org.br> Acesso em: 07 jan. 2015. 
CONFORTI, Luciana Paula. Trabalho escravo no Brasil contemporâneo: um olhar além da restrição da liberdade. 2014. Disponível em:

<http://trabalhoescravo.org.br/noticia/79>. Acesso em: 10 set. 2015.

COUTINHO, João Pereira. Os escravos. Folha de São Paulo. 2014. Disponível em <http://www1.folha.uol.com.br/colunas/joaopereiracoutinho/2014/02/1417274-osescravos.shtml>. Acesso em: 18 dez. 2014.

DUDH. Declaração Universal dos Direitos Humanos. 1948. Disponível em: <http://www.dudh.org.br/declaracao/>. Acesso em: 10 set. 2015.

HOLZ, Wantiul Luiz Cândido. Execução por quantia certa contra a fazenda pública. 2006. Dissertação de Mestrado. Programa de pós-graduação - mestrado. Área de concentração: políticas públicas e processo. Faculdade de Direito de Campos, Campos dos Goytacazes, 2006. Disponível em:

<http://www.fdc.br/Arquivos/Mestrado/Dissertacoes/Integra/WantuilLuizCandidoHolz. pdf>. Acesso em: 10 set. 2015.

JORNAL DO POVO. Agecom. Bahia terá núcleo especializado no combate de tráfico de pessoas. Jornal do Povo, Feira de Santana, 22 de março de 2011. Disponível em: <http://www.cljornal.com.br/antigo-site/noticia.php?id=9684>. Acesso em: 10 set. 2015.

MARANHÃO. Secretaria de Estado da Mulher. Maranhão instala o 16 Núcleo de Enfrentamento ao Tráfico de Pessoas do País. Disponível em: <http://www7.semu.ma.gov.br/index.php?option=com_content\&view=article\&id=314: maranhao-instala-o-16o-nucleo-de-enfrentamento-ao-trafico-de-pessoas-dopais\&catid=8:noticiaultima\&ltemid=90>. Acesso em: 10 set. 2015.

MATTOS, Paulo Henrique Costa. O trabalho escravo enquanto grave violação dos direitos humanos e a degradação social na região Araguaia Tocantins. Interface, Edição número 7, março de 2014. Disponível em: <http://revista.uft.edu.br/index.php/interface/article/view/695/391 >. Acesso em: 10 set. 2015.

MELO, Karine. Auditores do Trabalho e OIT lançam programa de reinserção de vítimas de trabalho escravo. 2013. Disponível em:

<http://www.ebc.com.br/noticias/politica/2013/05/auditores-do-trabalho-e-oit-lancamprograma-de-reinsercao-de-vitimas-

de<http://revista.uft.edu.br/index.php/interface/article/view/695/391>. Acesso em: 10 set. 2015.

MPT. Ministério Público do Trabalho. Trabalho escravo. Disponível em: <http://portal.mpt.mp.br/wps/portal/portal_mpt/mpt/area-atuacao/trabalhoescravo/!ut/p/z1/04_Sj9CPykssy0xPLMnMzz0vMAfljo8ziDd0NTDyd_A283b0DzA0cAw 19XT3dDY28jc31w_EqMDHVj6JEP1ABSL8BDuBoANQfhdcKF3MCCKBOJGRJQW5 ohEGmpylAduWVOQ!!/dz/d5/L2dBISEvZOFBIS9nQSEh/>. Acesso em: $18 \mathrm{dez}$. 2014.

MTE. Ministério do Trabalho e Emprego. Portaria no 540 de 15 de outubro de 
2004. Cadastro de Empregadores Infratores. Disponível em: <http://portal.mte.gov.br/data/files/FF8080812BE914E6012BF2B6EE26648F/p_2004 1015_540.pdf>. Acesso em: 10 set. 2015.

OIT. Organização Internacional do Trabalho. Estatísticas de Trabalho Forçado. Disponível em:

<http://www.oit.org.br/sites/all/forced_labour/oit/relatorio/indicadores.pdf>. Acesso em: 10 set. 2015.

. Organização Internacional do Trabalho. OIT apoia reinserção profissional de egressos do trabalho escravo. 2013. Disponível em:

<http://www.oit.org.br/content/oit-apoia-reinsercao-profissional-de-egressos-dotrabalho-escravo>. Acesso em: 10 set. 2015.

. Organização Internacional do Trabalho. Trabalho Forçado ou Obrigatório.

Convenção n. 29. Conferência Internacional do Trabalho (Genebra - 1930).

Disponível em < http://www.oitbrasil.org.br/node/449>. Acesso em: 18 dez. 2014.

OLIVEIRA, Luiza de Fátima Amorim. A erradicação do Trabalho Escravo no Maranhão. Repórter Brasil, 2011. Disponível em:

$<$ http://reporterbrasil.org.br/coetraes/wp-content/uploads/2014/08/Plano-EstadualMA.pdf >. Acesso em: 10 set. 2015.

PIOVESAN, Flávia; CARVALHO, Luciana Paula Vaz de. Direitos Humanos e Direito do Trabalho. São Paulo: Atlas, 2010.

PRUDENTE, Wilson. Crime de Escravidão. São Paulo: Lumen Juris, 2006.

SAKAMOTO, Leonardo. Trabalho Escravo no Brasil do século XXI. Brasília: Organização Internacional do Trabalho, 2007.

SARAIVA, Wellington C. Membro do MP Federal. Coordenador Assess.

Constitucional PGR. Brasília, 2009. Twitter. Disponível em:

<https://twitter.com/WSarai/status/520577769751605250>. Acesso em: 10 set. 2015.

SILVA, Marcello Ribeiro. Trabalho análogo ao de escravo rural no Brasil do século XXI: novos contornos de um antigo problema. 2010. Dissertação de Mestrado. Pró- Reitoria de Pesquisa e Pós-Graduação - PRPPG da Universidade Federal de Goiás - UFG, Goiânia, 2010. Disponível em:

<http://portal.mpt.mp.br/wps/wcm/connect/portal_mpt/35d284c9-cd7b-4889-81a5f3823d8e2270/Disserta\%C3\%A7\%C3\%A30\%2BTrabalho\%2BAn\%C3\%A1logo\%2Ba \%\%2Bde\%2Bescravo.pdf?MOD=AJPERES\&CONVERT_TO=url\&CACHEID=35d284 c9-cd7b-4889-81a5-f3823d8e2270>. Acesso em: 10 set. 2015.

TST. Tribunal Superior do Trabalho. Trabalho escravo, reincidência e perspectivas. 2013. Disponível em <http://www.tst.jus.br/noticias//asset_publisher/89Dk/content/trabalho-escravo-reincidencia-e-perspectivas>. Acesso em: $18 \mathrm{dez} .2014$.

. Tribunal Superior do Trabalho. TST firma termo de cooperação 
interinstitucional para reinserção social de egressos do trabalho escravo. 2015. Disponível em: <http://www.tst.jus.br/noticias/-

/asset_publisher/89Dk/content/id/14813003>. Acesso em: 10 set. 2015.

VITO, Palo Neto. Conceito Jurídico e Combate ao Trabalho Escravo

Contemporâneo. São Paulo: LTr, 2008. 